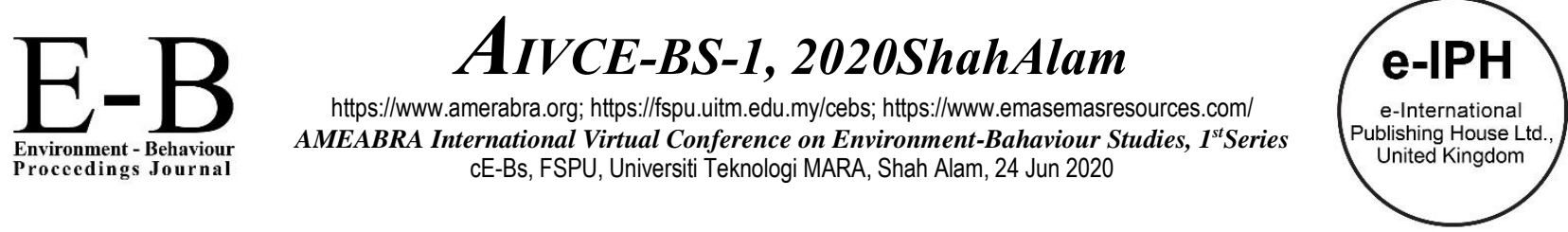

\title{
Risk Management Challenges in Malaysia's Landscape Architecture Project
}

\author{
Adam Aruldewan S.Muthuveeran 1, Osman Mohd Tahir ${ }^{1}$, Roziya Ibrahim 1, Mohd Zairul Mohd Noor 2 \\ 1 Department of Landscape Architecture, ${ }^{2}$ Department of Architecture, Faculty of Design and Architecture, \\ Universiti Putra Malaysia, 43400 Selangor, Malaysia
}

aruldewan@yahoo.com; osmanmt@upm.edu.my; roziya@upm.edu.my; m_zairul@upm.edu.my; Tel +6017-3125446

\begin{abstract}
This study aims to review current risk management challenges in Malaysia landscape architecture projects. This subject found to be lacking and yet essential to strategies for effective application. The data collection conducted through a semi-structured interview with twenty-four landscape architect professional based in the Klang Valley region. Then analysed using content and thematic analysis method. The research found that multiple challenges factor permits effective risk management application in the project. The study suggests for an extensive strategy to risk management application into the project to be formulated in enabling effective management of risk to improve project performances.
\end{abstract}

Keywords: managing risk; risk management; risk challenges; landscape architecture project

eISSN: 2398-4287C 2020. The Authors. Published for AMER ABRA cE-Bsby e-International Publishing House, Ltd., UK. This is an open access article under the CC BYNC-ND license (http://creativecommons.org/licenses/by-nc-nd/4.0/). Peer-review under responsibility of AMER (Association of Malaysian Environment-Behaviour Researchers), ABRA (Association of Behavioural Researchers on Asians) and cE-Bs (Centre for Environment-Behaviour Studies), Faculty of Architecture, Planning \& Surveying, UniversitiTeknologi MARA, Malaysia.

DOI: https://doi.org/10.21834/ebpj.v5i14.2162

\subsection{Introduction}

Landscape architectural practice has been part of environment behaviour to enhance inter-relationship between social and cultural factors and the physical aspects of the landscape environment. Recognising environmental issues such as conservation, pollution, energy conservation, housing, environmental risk, heritage and tourism developments; demand for more socially relevant landscape architecture projects spike over the decades. Landscape architecture projects are viewed as dynamic, with subjective outcomes and varied challenges due to the projects' uncertainty and complexity in nature, leading to multiple risks bound to happen. Consequent to this scenario added with the project processes, environment and stakeholders' factor putting risk in a landscape architecture project. Hence risk being managed earlier before it becomes an issue affecting the project's outcome. Malaysia landscape architecture project is part of the construction industry that recognised with a multitude of risks involved, commonly safety, financial, technical, quality and environmental (Adnan \& Rosman, 2018; Ansah, Sorooshian, Mustafa, \& Duvvuru, 2016; Fadzil, Noor, \& Rahman, 2017; Hasan, Othman, \& Ismail, 2018; Ismail, Ahmad, Janipha, \& Ismail, 2017; Kurzi \& Schroth, 2018; Marmaya \& Mahbub, 2018; Maruthaveeran, 2016; Mohit, 2018; Omer, Adeleke, \& Chia, 2019; Razi, Ali, \& Ramli, 2020; Saaidin, Endut, Samah, Ridzuan, \& Razak, 2016; Sani, Sharip, Othman, \& Hussain, 2018; Shafie, Omar, \& Karuppanan, 2018; Shamsudin \& Majid, 2019; Thani, Mohamad, \& Abdullah, 2017; Wena, Ismail, Hashim, \& Romeli, 2017).

Risk management is a crucial project knowledge area to manage these issues and their challenges beforehand. The primary purpose of risk management is to improve project performance via the systematic process of identifying, analysing and responding to the risk in order to achieve project objectives (APM, 2012; ISO 31000:2018, 2018; Keers \& van Fenema, 2018; Olechowski, Oehmen, Seering, \& Ben-Daya, 2016; PMI, 2017; Willumsen, Oehmen, Stingl, \& Geraldi, 2019). Malaysia risk management practice in a construction project is at the lowest application despite the availability of various risk management standard and guidelines in practice. Risk management still a rhetoric subject and not extensively practice to its full benefit. Reviewed there were enormous challenges that permit effective risk management application in Malaysia construction project, found in (Abdul-Rahman, Wang, \& Mohamad, 2015; Adnan \& Rosman, 2018;

eISSN: 2398-4287@ 2020. The Authors. Published for AMER ABRA cE-Bsby e-International Publishing House, Ltd., UK. This is an open access article under the CC BYNC-ND license (http://creativecommons.org/licenses/by-nc-nd/4.0/). Peer-review under responsibility of AMER (Association of Malaysian Environment-Behaviour Researchers), ABRA (Association of Behavioural Researchers on Asians) and cE-Bs (Centre for Environment-Behaviour Studies), Faculty of Architecture, Planning \& Surveying, UniversitiTeknologi MARA, Malaysia.

DOI: https://doi.org/10.21834/ebpj.v5i14.2162 
Fadzil et al., 2017; Goh \& Abdul-Rahman, 2013; Kang, Fazlie, Goh, Song, \& Zhang, 2015; Mohamed, Abd-Karim, Roslan, Mohd Danuri, \& Zakaria, 2014; Omer et al., 2019; Taofeeq, Adeleke, \& Lee, 2020). Understand the current managing risk practice and risk management application essential to project manager to strategies for effective risk management application. Contrarily, study on risk management application challenges directly related to landscape architecture project not extensively discussed in the literature.

Thus, this study aims to review current risk management challenges in Malaysia landscape architecture projects. The objectives to accomplish aims following, 1) to investigate challenges when managing risk, 2) to anticipate risk management application challenges, and 3) to determine ways overcoming the challenges. A review to Malaysia risk management application challenges in construction project conducted to relate with landscape architecture project context due to its closest interchangeable similarity.

\subsection{Challenges and Limitations of Risk Management Application in Malaysia}

Risk management has been practised in various construction projects worldwide, since the 80s (Flanagan, 2003) and proven to influence project performance. He further added that there no shortage of risk management system and project manager willing to use it. However, it has not been broadly practised in the Malaysian construction industry (Omer et al., 2019), and the industry seems to have a poor image in managing risk (Adnan \& Rosman, 2018). Several authors (Abdul-Rahman et al., 2015; Adnan \& Rosman, 2018; Fadzil et al., 2017; Goh \& Abdul-Rahman, 2013; Jusoff, Yusuwan, Adnan, \& Omar, 2008; Kang et al., 2015; Mohamed et al., 2014; Omer et al., 2019; Taofeeq et al., 2020) have attempted to provide an insight into the challenges and limitations of implementing risk management and the reasons for them in Malaysia's construction projects. Table 1 summarises the challenges and limitations of the risk management application in Malaysia.

Table 1. Challenges and limitations of the risk management application in Malaysia

\begin{tabular}{|c|c|c|}
\hline & Challenges and Limitations & Author \\
\hline \multirow{4}{*}{$\begin{array}{l}\text { Risk } \\
\text { management } \\
\text { system }\end{array}$} & $\begin{array}{l}\text { Application is mostly ill-structured, and no proper techniques are } \\
\text { adopted. }\end{array}$ & $\begin{array}{l}\text { Abdul-Rahman et al. (2015), Adnan \& Rosman (2018), Goh \& Abdul-Rahman } \\
\text { (2013), Kang et al. (2015), Omer et al. (2019) }\end{array}$ \\
\hline & Ineffective reporting, reviewing and monitoring risk management. & Jusoff et al. (2008), Mohamed et al. (2014) \\
\hline & Lack of/ no standard procedures and guidelines. & Jusoff et al. (2008), Mohamed et al. (2014) \\
\hline & Not frequently practised despite the availability. & Abdul-Rahman et al. (2015), Kang et al. (2015) \\
\hline \multirow[t]{5}{*}{$\begin{array}{l}\text { Managing risk } \\
\text { practice }\end{array}$} & Manages risk informally, incomplete and unstructured. & $\begin{array}{l}\text { Adnan \& Rosman (2018), Kang et al. (2015), Omer et al. (2019), Taofeeq et al. } \\
\text { (2020) }\end{array}$ \\
\hline & Applies straightforward, fast and inexpensive methods. & Adnan \& Rosman (2018), Fadzil et al. (2017), Omer et al. (2019) \\
\hline & Identifies risk not managed and left redundant. & Adnan \& Rosman (2018), Mohamed et al. (2014) \\
\hline & Risk only managed when it occurs and realised. & $\begin{array}{l}\text { Abdul-Rahman et al. (2015); Goh \& Abdul-Rahman (2013), Mohamed et al. (2014), } \\
\text { Omer et al. (2019) }\end{array}$ \\
\hline & Relies on the project manager's experience and justification. & Fadzil et al. (2017), Kang et al. (2015), Omer et al. (2019) \\
\hline \multirow{2}{*}{$\begin{array}{l}\text { Risk } \\
\text { knowledge }\end{array}$} & Limited skills in developing risk strategy and mitigation. & Abdul-Rahman et al. (2015), Adnan \& Rosman (2018), Taofeeq et al. (2020) \\
\hline & Lack of knowledge in risk management causes restriction of use. & $\begin{array}{l}\text { Abdul-Rahman et al. (2015), Adnan \& Rosman (2018), Fadzil et al. (2017), Goh \& } \\
\text { Abdul-Rahman (2013), Mohamed et al. (2014), Taofeeq et al. (2020) }\end{array}$ \\
\hline \multirow{4}{*}{$\begin{array}{l}\text { Exposure and } \\
\text { experience }\end{array}$} & No expertise to lead. & Jusoff et al. (2008) Mohamed et al. (2014) \\
\hline & Low-risk practice exposure. & Abdul-Rahman et al. (2015), Goh \& Abdul-Rahman (2013), Taofeeq et al. (2020) \\
\hline & Lack of competency in identifying risk at an early stage. & Mohamed et al. (2014) \\
\hline & Still a new concept. & Jusoff et al. (2008) Kang et al. (2015), Omer et al. (2019) Taofeeq et al. (2020) \\
\hline \multirow[t]{4}{*}{ Awareness } & Comfortable with traditional culture and reluctant to change. & $\begin{array}{l}\text { Abdul-Rahman et al. (2015), Adnan \& Rosman (2018), Fadzil et al. (2017), Goh \& } \\
\text { Abdul-Rahman (2013), Kang et al. (2015), Taofeeq et al. (2020) }\end{array}$ \\
\hline & $\begin{array}{l}\text { Resistance and unsupportive top management and other } \\
\text { industry personnel. }\end{array}$ & $\begin{array}{l}\text { Jusoff et al. (2008), Kang et al. (2015), Mohamed et al. (2014), Taofeeq et al. } \\
(2020)\end{array}$ \\
\hline & $\begin{array}{l}\text { Lack of positive attitude - associated with time and cost } \\
\text { consuming. }\end{array}$ & $\begin{array}{l}\text { Abdul-Rahman et al. (2015), Fadzil et al. (2017), Goh \& Abdul-Rahman (2013), } \\
\text { Kang et al. (2015), Taofeeq et al. (2020) }\end{array}$ \\
\hline & Low awareness of its benefits and hardly justified objective value. & $\begin{array}{l}\text { Abdul-Rahman et al. (2015), Fadzil et al. (2017), Goh \& Abdul-Rahman (2013), } \\
\text { Kang et al. (2015), Mohamed et al. (2014), Omer et al. (2019) Taofeeq et al. (2020) }\end{array}$ \\
\hline
\end{tabular}

Risk management is still a rhetorical subject in the Malaysian construction industry due to the lack of knowledge and awareness of its benefits, leading to reluctance to adopt it (Adnan \& Rosman, 2018; Jusoff et al., 2008; Siang \& Ali, 2012). In the Malaysian construction industry, risk management is adapted differently and based on company policies, allocation of resources, and nature of projects (Jusoff et al., 2008; Taofeeq et al., 2020). They generally adopt simple, quick, reasonable, and inexpensive methods to identify risk instead of managing it as a whole process (Adnan \& Rosman, 2018; Siang \& Ali, 2012).

All the authors agreed that the biggest challenge in implementing risk management is that there is no formal risk management guidelines and standards to be applied in Malaysia's construction sector. Risk is being managed by only specific organisations and on certain project scale sizes. It is not managed comprehensively and does not follow the suggested process due to the lack of knowledge of risk management implementation and lack of awareness of its benefits. Hence, construction project practitioners are reluctant to 
implement risk management in their projects. Similar to construction projects, there is no substantial evidence that formal risk management applied in landscape architecture projects.

\subsection{Methodology}

The study methodology engaged an exploratory case study (Yin, 2016). The study takes a four-stage procedure, namely, preliminary study, data collection, data analysis, and interpretation, as depicted in Figure 2. Firstly, a preliminary study reviewing study background, the need, identify the gap and develop aim and objectives. Data collected through a semi-structured interview with twenty-four landscape architect professional based in the Klang Valley region. The interview audios and project documents recorded; transcribed into the text; documented and organised in ATLAS.ti 8 research software. Then, the data analysis employed a content analysis for describing and interpreting deductive codes, categorising and finalising the themes (Mayring, 2014). Further, a thematic analysis was then employed to synthesise and draw thematic map between the themes while seeking inductive codes. The analysis includes exploring the relationship between the studied subject categories and seeks pattern (Maguire \& Delahunt, 2017). Finally, finding interpretation mapped and reported to discuss risk management practice, application challenges and improvement. The conclusion draws to answer study objectives. This study could become a prominent point for discussion and a priority in future. This study limited by, 1) landscape architecture project management, 2) case project focused on preference on urban landscape architecture, and 3) challenges scope bound to landscape architectural practitioner's perspective.
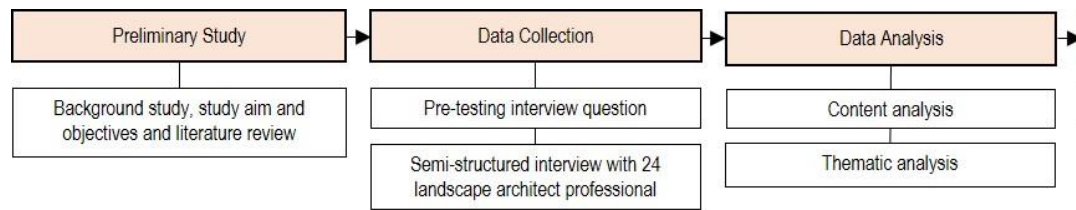

Fig 1. Study procedure

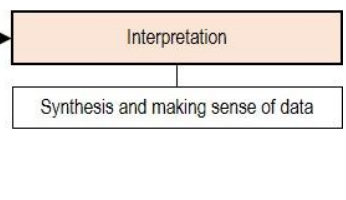

\subsection{Findings}

Interviewees asked of their opinions regarding risk management application challenges. Their responses discussed in three aspects, namely, challenges when managing risk, anticipated risk management application challenges, and suggestions for overcoming the challenges.

\subsection{Managing Risk Challenges}

The study identified several challenges faced by the interviewees when managing the project risks. The challenges are grouped into six areas, as shown in Table 2 below.

Table 2. Managing risk challenges

\begin{tabular}{|c|c|c|}
\hline Interviewees & Interviewees' Feedback & Challenges \\
\hline L02, L03, L04, L05, L12, L13, L17, L20, L22 & Client not responsive to identified risk. & Lack of stakeholder support \\
\hline L02, L13 & Lack of mandate and commitment by the client over the risk. & \\
\hline L02, L20 & No contingencies or additional resources allowed to treat the identified risk. & \\
\hline L03, L12, L17, L20 & Stakeholder pushing away risk ownership - one party dealt with it. & \\
\hline L04, L05, L12, L20, L22 & Difficulty in convincing client to agree with risk treatment. & \\
\hline L01. L03, L05, L08, L19, L23 & Inexperienced project manager handing project risk - risk unattended. & Lack of managing risk \\
\hline L01, L23 & Incompetency to identified risk at early project lifecycle. & experience \\
\hline L12, L20, L23 & Poor risk treatment strategy. & \\
\hline L03, L07, L19, L20 & Challenging to manage - Landscape scope uncertainties and subjective. & \\
\hline L01, L03, L06, L08, L10, L11, L16, L21 & No specific formal standard procedures and guidelines practised. & No formal risk management \\
\hline L03, L10, L11, L16 & Heavy reliance on the project manager's experience and thinking process. & guideline \\
\hline L11, L16 & Absent of structured risk process. & \\
\hline L21 & None enforcement of risk management policy. & \\
\hline L01 & $\begin{array}{l}\text { Risk management guideline deemed generic - not suitable for the landscape architecture } \\
\text { context. }\end{array}$ & \\
\hline L01, L02, L07, L15, L20, L24 & Miscommunication causing ineffective risk process. & Communication \& \\
\hline L02, L15, L24 & Identified risk not recorded and not retrievable for treatment at later phases of the project. & information barrier \\
\hline L15, L20, L24 & $\begin{array}{l}\text { Project manager not informed of potential risk by others - unknown site condition, utilities } \\
\text { underneath the ground, and changes of the significant scope. }\end{array}$ & \\
\hline L01, L07 & Poor integration between project parties - miscommunication and information sharing. & \\
\hline L01, L03, L08, L22, L23 & No attempt to foresee the risk earlier and only managing it when it materialised. & Risk managed reactively \\
\hline L08, L23 & Unavailability of cost and time allocation to treat the surprise risk. & \\
\hline L01, L22 & Poor anticipation and forecasting risk beforehand - inexperienced. & \\
\hline L08, L20 & The limited risk treatment strategy option towards risks caused by others. & Limited scope of managing \\
\hline L10, L14, L20 & $\begin{array}{l}\text { Small content of landscape architecture scope compared to architecture or engineering - } \\
\text { forced to accept risk rather than avoiding, mitigating, or transferring it. }\end{array}$ & \\
\hline
\end{tabular}




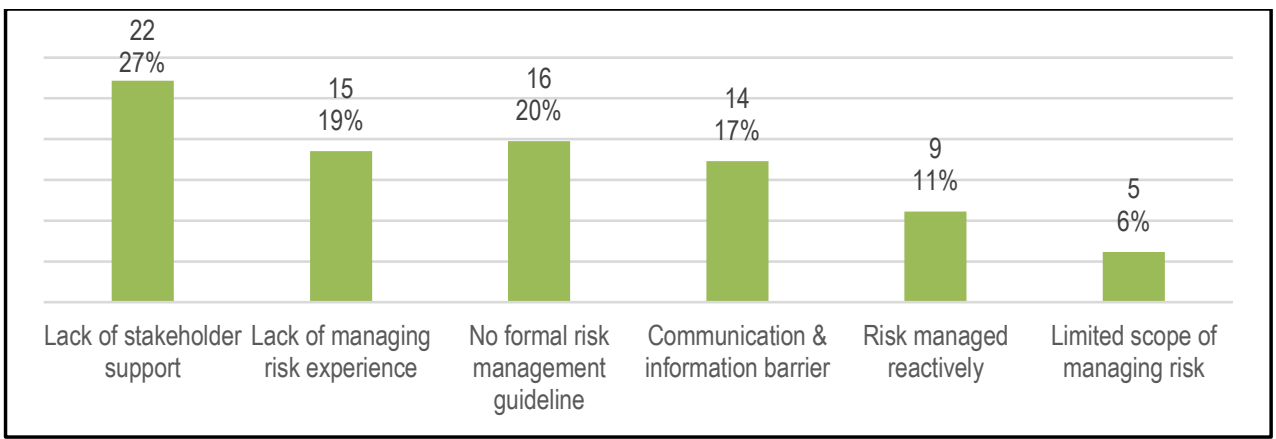

Fig 2. Summary of managing risk challenges

As shown in Figure 2, lack of stakeholder support (27\%), lack of experience (19\%), and no formal guideline (20\%) identified as the most common challenges faced the interviewees when managing risk in a landscape architecture project. The lack of stakeholder support towards the identified risk further affecting risk miscommunication, information sharing barrier, and limited contingencies allocation to treat the risk. These challenges are similar to the challenges faced by Malaysia's construction industry, as highlighted in the literature. No common formal risk management application found to constrain the challenges against effective risk management.

\subsection{Anticipated Risk Management Application Challenges}

The study identified several anticipated risk management application challenges in landscape architecture projects, as expressed by the interviewees. The study coded 143 anticipated challenges and then grouped them into six areas, as shown in Table 3.

Table 3. Anticipated risk management application challenges

\begin{tabular}{|c|c|c|}
\hline Interviewees & Interviewees' Feedback & Anticipated Challenges \\
\hline L03, L06, L22 & $\begin{array}{l}\text { Possible rejection - associate risk management as another system for scrutinising project } \\
\text { performance. }\end{array}$ & $\begin{array}{l}\text { Lack of support and } \\
\text { acceptance }\end{array}$ \\
\hline L09, L10, L15, L16, L17, L18, L24 & Another redundant management system - impractical to project delivery. & \\
\hline L17, L20, L22, L24 & The application may disrupt ongoing project progress. & \\
\hline $\begin{array}{l}\text { L05, L09, L11, L13, L15, L16, L19, } \\
\text { L20, L22 }\end{array}$ & Local construction culture - work with the minimal system and standard. & \\
\hline L05, L09, L13, L20 & Unsupportive client towards application output. & \\
\hline L15 & $\begin{array}{l}\text { Client preference towards objective output and financial tolerance management system like value } \\
\text { engineering management and cost management. }\end{array}$ & \\
\hline L05, L13, L19, L22 & Comfortable with the current operating system. & \\
\hline L06, L09, L15, L16, L17, L21, L24 & Poor motivation and unwilling to learn. & \\
\hline$(\mathrm{L} 01, \mathrm{~L} 09, \mathrm{~L} 23$ & Fail to understand the application benefits to project and organisation. & Lack of awareness \\
\hline $\begin{array}{l}\text { L03, L05, L09, L15, L17, L20, L22, } \\
\text { L24 }\end{array}$ & Sceptical on the application - may delay decision making and limit creativity. & \\
\hline L15, L20, L22 & May limit project decision making and flexibility due to its rigid structured process. & \\
\hline L09, L07, L15, L20 & May limit business opportunities - too concerned about risk rather than the opportunities ahead. & \\
\hline L01, L09, L10, L16, L20, L24 & Rejection - application rarely or none used in the landscape industry. & \\
\hline L01, L10, L16, L18, L20, L22 & Irrelevant application - landscape scope is small, the risk is insignificant, and risk impact is minor. & \\
\hline $\begin{array}{l}\text { L02, L03, L06, L17, L18, L20, L21, } \\
\text { L24 }\end{array}$ & Satisfied with the current project management operation. & Resistance to change \\
\hline L09, L16, L20 & Current project operation is sufficient to manage risk. & \\
\hline L16, L21, L23 & Rely on the project manager's experience and knowledge. & \\
\hline L10, L16, L18, L20, L24 & Unwilling to allocate time and cost. & \\
\hline L16 & Challenging to attain the internal operation team's mandate and commitment. & \\
\hline L13, L18 & Then the stringent procedure of government client - application disregarded. & \\
\hline $\begin{array}{l}\text { L02, L05, L06, L09, L11, L15, L17, } \\
\text { L18, L20 }\end{array}$ & Regarded risk management application as consuming time and efforts - limited budget. & Lack of resources \\
\hline L06, L09, L10, L11, L17, L18 & Project nature that is rushing and time constraint - no time allowance. & \\
\hline $\begin{array}{l}\text { L04, L05, L06, L09, L10, L11, L15, } \\
\text { L17, L20, L24 }\end{array}$ & Worried the application requires extensive paperwork and protocol, further delaying the project. & \\
\hline L06, L16, L17 & Increases business cost - to employ a specialist to manage risk. & \\
\hline L17, L20 & Limited staff and time constraint in handling multiple projects - application may be put aside. & \\
\hline $\begin{array}{l}\text { L01, L05, L10, L15, L17, L19, L20, } \\
\text { L21 }\end{array}$ & Lack of risk and risk management knowledge. & Lack of knowledge \\
\hline L04, L09, L21 & Lack of risk management exposure - application is new to the industry. & \\
\hline L06, L15, L17, L21 & Need extensive time to understand the risk process. & \\
\hline L16, L19 & $\begin{array}{l}\text { Difficult to transfer the risk management knowledge to the organisation's project team - to junior and } \\
\text { non-technical staff. }\end{array}$ & \\
\hline
\end{tabular}


The results in Figure 3 indicate that the challenges in risk management application vary due to both internal and external factors. The interviewees were most concerned about the lack of support and acceptance towards the risk management application (27\%). Poor awareness $(21 \%)$ of the risk management concept and benefits further inhibits an effective risk management application. Lack of resources $(21 \%)$, such as limited budget and time allocation, is also a challenge to the risk management practice. Resistance to change, lack of expertise and lack of knowledge are the remaining challenges in adopting a risk management application. The anticipated application challenges are similar to the challenges faced by Malaysia's construction industry, as highlighted in the literature. The anticipated risk management application challenges are also similar to the previously discussed project challenges mentioned which relate to client poor engagement and awareness towards the landscape scope.

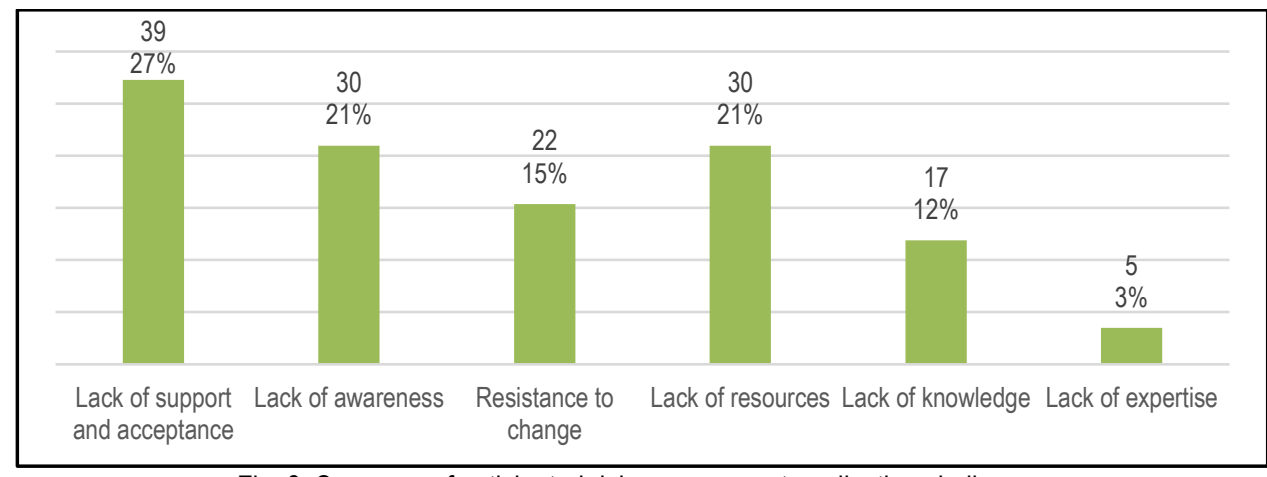

Fig. 3. Summary of anticipated risk management application challenges

\subsection{Suggestions for Overcoming Challenges}

The interviewees asked to suggest measures to overcome the identified challenges. Their suggestions divided into two outcomes, namely the development of a risk management framework and the improvement to risk management practices, as shown in Table 4.

Table 4. Interviewees' suggestions for overcoming challenges

\begin{tabular}{|c|c|c|}
\hline & Suggestions To Overcome Challenges & Interviewees \\
\hline in an & anagement Framework & \\
\hline Simplified Process & $\begin{array}{l}\text { A more straightforward structure and flow process to minimise the time to apply and ease understanding for all. } \\
\text { A system that is more streamlined for ease implementation. } \\
\text { A framework that does not produce massive paperwork and stringent procedure. }\end{array}$ & $\begin{array}{l}\text { L09, L12, L24 } \\
\text { L10 } \\
\text { L06, L15 }\end{array}$ \\
\hline Flexibility in Practice & $\begin{array}{l}\text { A flexible process that adjusted according to the project scope and context. } \\
\text { Eliminate the rigid process and documentation as the landscape trait is subjective and vague. } \\
\text { Risk management methodology should be adjustable to suit varying projects. } \\
\text { The framework can be amended in time as the organisation matures. }\end{array}$ & $\begin{array}{l}\text { L02, L13,L } 24 \\
\text { L06, L15 } \\
\text { L11 } \\
\text { L22 }\end{array}$ \\
\hline $\begin{array}{l}\text { Align with the } \\
\text { Organisation's Context } \\
\end{array}$ & $\begin{array}{l}\text { Align with the organisation's context - culture, business operation, and objective. } \\
\text { Suitable for day-to-day project operation application. }\end{array}$ & $\begin{array}{l}\text { L08, L18, L20 } \\
\text { L18 }\end{array}$ \\
\hline Managing Risk Practice II & mprovement & \\
\hline Mandate and Commitment & $\begin{array}{l}\text { Mandate and commitment as part of the organisation's objectives. } \\
\text { Involve all the project parties and share ownership. } \\
\text { Assign personnel that is held accountable and responsible within the organisation to monitor risk. } \\
\text { Periodical review of the risk management application by a competent and knowledgeable manager. } \\
\text { Regular monitoring of all the project stakeholders and seek their conformity. }\end{array}$ & $\begin{array}{l}\text { L03, L05, L18, L19, } \\
\text { L20, L22, L23 } \\
\text { L20, L23 } \\
\text { L05, L17, L20, L23 } \\
\text { L05, L17, L20, L23 } \\
\text { L22 }\end{array}$ \\
\hline Enhance Awareness & $\begin{array}{l}\text { Application to start early, progressively and with constant monitoring. } \\
\text { To be part of the education curriculum and professional courses. } \\
\text { Continued training and communication to enhance risk management exposure. }\end{array}$ & $\begin{array}{l}\text { L01, L23 } \\
\text { L03, L04, L19, L20 } \\
\text { L04, L19, L20 }\end{array}$ \\
\hline $\begin{array}{l}\text { Integration to Current } \\
\text { Project Process }\end{array}$ & $\begin{array}{l}\text { Integrated into the project process rather than having a standalone management system. } \\
\text { Best practices approach adopted to suit the organisation's context. } \\
\text { Refer to other closest industry applications and modify to suit internally. }\end{array}$ & $\begin{array}{l}\text { L02, L18 } \\
\text { L05 } \\
\text { L02, L19 }\end{array}$ \\
\hline $\begin{array}{l}\text { Communication \& } \\
\text { Information Management }\end{array}$ & $\begin{array}{l}\text { Documentation and recording of risk management activities - for future project reference. } \\
\text { All project parties should be well informed of the risk process and outcome to minimise miscommunication. } \\
\text { Continuous communication - internal and external to the organisation. }\end{array}$ & $\begin{array}{l}\text { L06 } \\
\text { L13, L20, L23 } \\
\text { L12 }\end{array}$ \\
\hline
\end{tabular}

The majority of the interviewees suggest for the risk management framework development and risk management practices improvement considered in formulating the best strategy integrating risk management into landscape architecture projects. They agreed 
that a particular risk management framework developed to suit the landscape architecture context. The new risk management framework should be flexible, simplified, and aligned with the organisation's context. Besides framework development, improvement in risk management practices can be achieved by enhancing the risk mandate and commitment, creating awareness, integrating to current processes, and initiating communication and information management. These steps will ensure the effectiveness of the developed risk management application. The suggested risk management framework development and risk management practice improvement were considered in developing an effective risk management application, as illustrated in Figure 4.

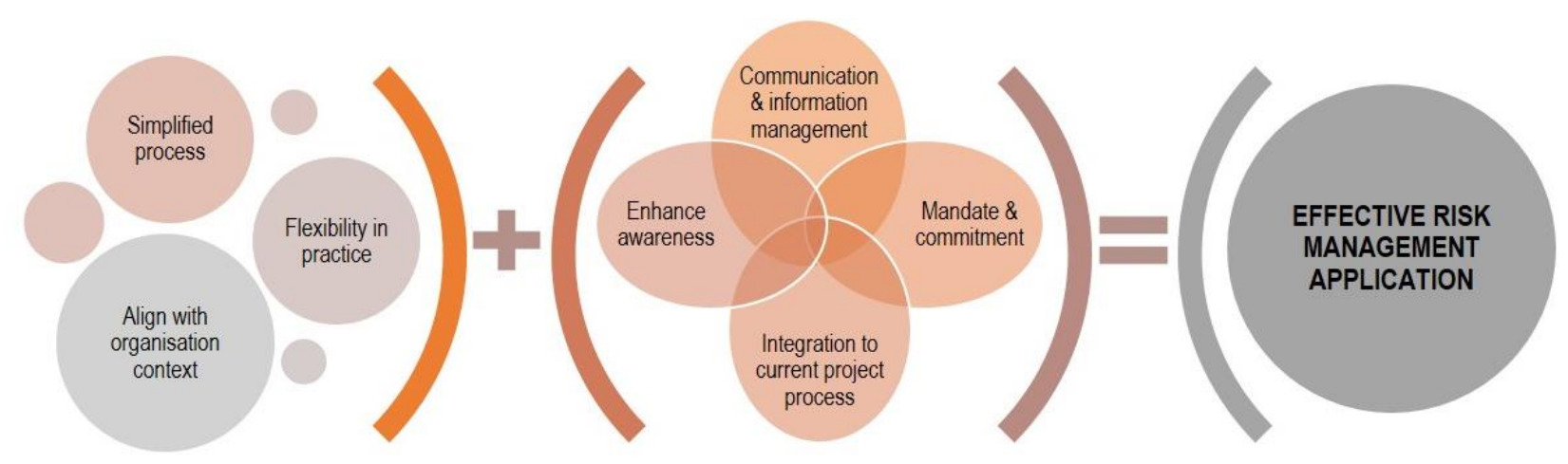

Development of a Risk Management Framework

Managing Risk Practice Improvement

Fig. 4. Suggestions for an effective risk management application

\subsection{Discussion}

Reviewed lack of stakeholder's support, lack of risk experience, communication barrier and scope definition found to be primary challenges when managing risk. The challenges observed related to human factor reason from project culture, personal perception and poor client-consultant engagement. Meanwhile, the mismanaged project risk further implicate effective risk management application. Lack of support, acceptance, resistance to change, poor risk management awareness, lack of knowledge, resources and expertise constrained effective risk management application. Added up to all identified challenges, the most significant risk management application challenges are there is no formal risk management system applied into landscape architecture project. This similar challenges found in Malaysia construction project where risk-managed reactively, ill-structured process and informal practice manner due to unavailable formal risk management application (Abdul-Rahman et al., 2015; Adnan \& Rosman, 2018; Fadzil et al., 2017; Goh \& Abdul-Rahman, 2013; Kang et al., 2015; Mohamed et al., 2014; Omer et al., 2019; Taofeeq et al., 2020).

As a result, the mismanaged project risk and ineffective risk management application challenge subsequently impact the project performances. Beyond the project completion, the hidden project risk that project failed to unanticipated will potentially lead to major consequences such as litigation implication, environmental degradation, injury, loss of property and socio-culture. Therefore, there is a need to raise the awareness of landscape architect professionals in Malaysia about the importance of risk management application and employing the appropriate method to manage project risk. Suggestion to overcome managing risk practices and risk management implementation challenges considered in risk management application into landscape architectural project. The improvement of managing risk practice by enhancing risk mandate and commitment, awareness, integration to the current process, communication and information management. An application opted to be flexible, simplified and tailored with organisation context to enhance risk management implementation.

\subsection{Conclusion \& Recommendations}

The study surmised that multiple challenges factor permits effective risk management application in landscape architecture project due to no formal risk management applied. Although formal risk management processes introduced, however, most risk management is practised in an ill-structured method and usually implemented informally. This study provides significant and valuable insight into a practical knowledge of current risk management application challenges and improvement in Malaysia landscape architecture project. By identifying actual industry challenges, an extensive strategy to risk management application into landscape architecture project formulated. For effective risk management application, recommended the project organisation to have a formal risk management system about landscape architectural context.

Further study engaged in the formulation of the best strategy to risk management integration into landscape architecture project management. This essential to landscape architecture project manager managing their risk effectively to improve project performances. 


\section{Acknowledgement}

We appreciate the financial support of this study from Geran Putra - Inisiatif Putra Siswazah (GP-IPS), Universiti Putra Malaysia (Project Number: GP-IPS/2018/9617500).

\section{References}

Abdul-Rahman, H., Wang, C., \& Mohamad, F. S. (2015). Implementation of Risk Management in Malaysian Construction Industry: Case Studies. Journal of Construction Engineering, 2015(1), 7. https://doi.org/10.1155/2015/192742

Adnan, H., \& Rosman, M. R. (2018). Risk management in Turnkey projects in Malaysia. WSEAS Transactions on Business and Economics, $15,35-43$.

Ansah, R. H., Sorooshian, S., Mustafa, S. Bin, \& Duvvuru, G. (2016). Assessment of Environmental Risks in Construction Projects: A Case of Malaysia. In Proceedings of the International Conference on Industrial Engineering and Operations Management (pp. 752-763).

APM. (2012). APM Body of Knowledge. APM Body Of Knowledge (6th ed.). Buckinghamshire: Association for Project Management https://doi.org/10.1080/10894160.2010.508411

Fadzil, N. S., Noor, N. M., \& Rahman, I. A. (2017). Need of risk management practice amongst bumiputera contractors in Malaysia construction industries. In IOP Conference Series: Materials Science and Engineering (Vol. 271, p. 7). https://doi.org/10.1088/1757-899X/271/1/012035

Flanagan, R. (2003). Managing Risk For An Uncertain Future - A Project Management Perspective. UK: School of Construction Management and Engineering; The University of Reading.

Goh, C. S., \& Abdul-Rahman, H. (2013). The Identification and Management of Major Risks in Malaysian Construction Indusrty. Journal of Construction in Developing Countries, 18(1), 19-32.

Hasan, R., Othman, N., \& Ismail, F. (2018). Choosing Tree for Urban Fabric: Role of Landscape Architect. In 6th AicQoL2018Perhentianlsland, 03-04 March 2018 / EBPJ, 3(7) (pp. 199-207).

Ismail, F., Ahmad, N., Janipha, N. A. I., \& Ismail, R. (2017). The Behavioural Factors ' Characteristics of Safety Culture. Journal of ASIAN Behavioural Studies (JABs), 2(4), 91-98.

ISO 31000:2018. (2018). ISO 31000:2018 Risk management - Guidelines. (ISO/TC 262 Risk Management, Ed.) (2nd ed.). Geneva 20: International Organization for Standardization (ISO). Retrieved from www.iso.org

Jusoff, K., Yusuwan, N. M., Adnan, H., \& Omar, A. F. (2008). Clients' Perspectives of Risk Management Practice in Malaysian Construction Industry. Journal Politic and Law, 1(3), 121-130. https://doi.org/10.5539/jpl.v1n3p121

Kang, B. G., Fazlie, M. A., Goh, B. H., Song, M. K., \& Zhang, C. (2015). Current Practice of Risk Management in the Malaysia Construction Industry - The Process and Tools/Techniques. International Journal of Structural and Civil Engineering Research, 4(4), 371-377. https://doi.org/10.18178/ijscer.4.4.371-377

Keers, B. B. M., \& van Fenema, P. C. (2018). Managing risks in public-private partnership formation projects. International Journal of Project Management, 36(6), 861875. https://doi.org/10.1016/j.jproman.2018.05.001

Kurzi, N. S., \& Schroth, O. (2018). Maintenance and Personal Safety in Neighborhood Parks: A literature and case study of MPSJ. Asian Journal of Quality of Life (AjQoL), 3(13), 107-116. https://doi.org/10.21834/ajqol.v3i13.167

Maguire, M., \& Delahunt, B. (2017). Doing a Thematic Analysis: A Practical, Step-by-Step. The All Ireland Journal of Teaching and Learning in Higher Education, 8(3) 3351-33514. Retrieved from http://ojs.aishe.org/index.php/aishe-j/article/view/335

Marmaya, E. A., \& Mahbub, R. (2018). Evaluation of Environmental Impact and Risk Assessment Methods of Industrial Buildings in Malaysia. Asian Journal of Quality of Life (AjQoL), 3(13), 39-47. https://doi.org/10.21834/ajqol.v3i13.160

Maruthaveeran, S. (2016). The Perception of Social Safety in a Green Environment: A preliminary study at the Kepong Metropolitan Park. Asian Journal of EnvironmentBehaviour Studies (AjE-Bs), 1(1), 99-111. https://doi.org/10.21834/aje-bs.v1i1.171

Mayring, P. (2014). Qualitative Content Analysis : Theoretical Foundation, Basic Procedures and Software Solution. Klagenfurt: Social Science Open Access Repository (SSOAR). https://doi.org/http://dx.doi.org/10.4135/9781446282243.n12

Mohamed, O., Abd-Karim, S. B., Roslan, N. H., Mohd Danuri, M. S., \& Zakaria, N. (2014). Risk management: Looming the modus operandi among construction contractors in Malaysia. International Journal of Construction Management, 15(1), 82-93. https://doi.org/10.1080/15623599.2014.967928

Mohit, M. A. (2018). Quality-of-Life Studies in Natural and Built Environment : Challenges and emerging issues. Asian Journal of Behavioural Studies (AjBeS), 3(10), 147157

Olechowski, A., Oehmen, J., Seering, W., \& Ben-Daya, M. (2016). The professionalization of risk management: What role can the ISO 31000 risk management principles play? International Journal of Project Management, 34(8), 1568-1578. https://doi.org/10.1016/j.jproman.2016.08.002

Omer, M. S., Adeleke, A. Q., \& Chia, K. L. (2019). Level of Risk Management Practive in Malaysia Construction INdustry From A Knowledge-Based Perspective. Journal of Architecture, Planning and Construction Management, 9(1), 112-129.

PMI. (2017). A Guide To The Project Management Body Of Knowledge (PMBOK Guide). (PMBOK, Ed.) (6th ed.). Pennsylvania 19073-3299 USA: Project Management 
Institute, Inc. https://doi.org/10.1002/pmj.21345

Razi, P. Z., Ali, M. I., \& Ramli, N. I. (2020). Incorporation of Risk Index for Risk Response and Risk Mitigation Strategies of Public-Private Partnership (PPP) Housing Construction Project in Malaysia. In IOP Conference Series: Materials Science and Engineering (Vol. 712, p. 012031). https://doi.org/10.1088/1757-899x/712/1/012031

Saaidin, S., Endut, I. R., Samah, S. A. A., Ridzuan, A. R. M., \& Razak, N. N. A. (2016). Risk Variable On Contractor's Tender Figure In Malaysia. Jurnal Teknologi (Sciences \& Engineering), 2(78:5), 85-89. https://doi.org/eISSN 2180-3722

Sani, J. A., Sharip, N. A. A., Othman, N., \& Hussain, M. R. M. (2018). Relationship between Types of Organization with the Quality of Soft-scape Construction Work in Malaysia. Asian Journal of Quality of Life (AjQoL), 3(12), 137-146. https://doi.org/10.21834/ajqol.v3i12.150

Shafie, F. A., Omar, D., \& Karuppanan, S. (2018). Environmental Risk Evaluation of a Sanitary Landfill using Life Cycle Analysis Approach. Asian Journal of EnvironmentBehaviour Studies (AjE-Bs), 3(8), 89-95. https://doi.org/10.21834/aje-bs.v3i8.282

Shamsudin, N. M., \& Majid, F. A. (2019). Effectiveness of Construction Safety Hazards Identification in Virtual Reality Learning Environment. In 8th AcEBs2019Langkawilsland, Malaysia 18-19 Dec 2019 / E-BPJ, 4(12) (pp. 375-381).

Siang, L. C., \& Ali, A. S. (2012). Implemention of risk management in the malaysian construction industry. Journal of Surveying, Construction \& Property, 3(1), 1-15. https://doi.org/10.1155/2015/192742

Taofeeq, D. M., Adeleke, A. Q., \& Lee, C. K. (2020). The synergy between human factors and risk attitudes of Malaysian contractors': Moderating effect of government policy. Safety Science, 121(September 2019), 331-347. https://doi.org/10.1016/j.ssci.2019.09.016

Thani, S. K. S. O., Mohamad, N. H. N., \& Abdullah, S. M. S. (2017). Influence of Urban Landscapes to Microclimatic Variances in a Tropical City. Asian Journal of Behavioural Studies (AjBeS), 2(7), 31-41.

Wena, J., Ismail, F., Hashim, N., \& Romeli, N. (2017). Adaptation Criteria towards Quality Culture for the Malaysian Contractors. In 5th AicQoL2017Bangkok, 25-27 February 2017 / E-BPJ, 2(5) (pp. 79-83). e-IPH Ltd. https://doi.org/10.21834/e-bpj.v2i5.676

Willumsen, P., Oehmen, J., Stingl, V., \& Geraldi, J. (2019). Value creation through project risk management. International Journal of Project Management, 37(5), $731-$ 749. https://doi.org/10.1016/j.jproman.2019.01.007

Yin, R. K. (2016). Qualitative Research from Start to Finish (2nd ed.). New York, NY: The Guilford Press. https://doi.org/10.1007/s13398-014-0173-7.2 